\title{
ERRATUM
}

Kai Bötzel · Patrick Feise · Ognyan I. Kolev

Siegbert Krafczyk • Thomas Brandt

\section{Postural reflexes evoked by tapping forehead and chest}

Published online: 24 July 2001

(C) Springer-Verlag 2001

\section{Exp Brain Res (2001) 138:446}

The first name of the third author was misspelled. The correct name is as follows: Ognyan I. Kolev.

The online version of the original article can be found at http://dx.doi.org/10.1007/s002210100726

K. Bötzel ( $)$ P. Feise $\cdot$ S. Krafczyk · T. Brandt

Department of Neurology, Ludwig-Maximilians-Universität, Klinikum Grosshadern, 81377 Munich, Germany e-mail: kboetzel@brain.nefo.med.uni-muenchen.de Tel.: +49-89-70951, Fax: +49-89-70953677

O.I. Kolev

Department of Neurology, University of Medicine, Sofia, Bulgaria 